\title{
Chemical Experiments with Superheavy Elements
}

\author{
Andreas Türler*
}

\begin{abstract}
Unnoticed by many chemists, the Periodic Table of the Elements has been extended significantly in the last couple of years and the 7th period has very recently been completed with eka-Rn (element 118) currently being the heaviest element whose synthesis has been reported. These 'superheavy' elements (also called transactinides with atomic number $\geq 104$ (Rf)) have been artificially synthesized in fusion reactions at accelerators in minute quantities of a few single atoms. In addition, all isotopes of the transactinide elements are radioactive and decay with rather short half-lives. Nevertheless, it has been possible in some cases to investigate experimentally chemical properties of transactinide elements and even synthesize simple compounds. The experimental investigation of superheavy elements is especially intriguing, since theoretical calculations predict significant deviations from periodic trends due to the influence of strong relativistic effects. In this contribution first experiments with hassium (Hs, atomic number 108), copernicium (Cn, atomic number 112) and element 114 (eka-Pb) are reviewed.
\end{abstract}

Keywords: Relativistic effects · Superheavy elements · Transactinides

\section{Introduction}

Where does the Periodic Table of the Elements end? What is the heaviest element in the Periodic System? Are there still undiscovered ones to be found in nature? Is there an 8 th period and how many elements will it contain? Will we need to introduce the superactinides starting with atomic number 121 ? Will the current principles governing the groups and periods of the Periodic Table still be valid for the heaviest elements and what defines the place an element occupies in the Periodic System? These intricate questions are the topic of current research in nuclear chemistry. Fig. 1 shows a modern Periodic Table.

The nuclide ${ }^{244} \mathrm{Pu}$, with a radioactive half-life of 81.2 million years could still be present on earth as a primordial element or be of cosmic origin due to explosive stellar nucleosynthesis, for example, from a nearby supernova that occurred after the formation of our solar system. Indeed, a concen-

\footnotetext{
${ }^{\star}$ Correspondence: Prof. Dr. A. Türler Laboratory of Environmental Chemistry and Radiochemistry

Department of Chemistry and Biochemistry, Bern University and Department of Biology and Chemistry, Paul Scherrer Institute

Freiestr. 3

$\mathrm{CH}-3012$ Bern

Tel.: + 41316314264

Fax: + 41563102404

E-mail: Andreas.Tuerler@psi.ch
}

tration of about 2500 atoms ${ }^{244} \mathrm{Pu}$ per gram of Bastnaesite, a mineral highly enriched in rare earth elements, was reported nearly 40 years ago. ${ }^{[2]}$ However, a recent search for ${ }^{244} \mathrm{Pu}$ in Bastnaesite from same mine using accelerator mass spectrometry remained negative with a detection limit of less than 550 atoms per gram. ${ }^{[3]}$

Thus, all known elements heavier than $\mathrm{Pu}$ are man-made. The last element that can be produced in weighable quantities is fermium with atomic number 100 . It can be produced by breeding in high-flux nuclear reactors and quantities of few nanograms have been isolated and supplied for chemical experiments, i.e. for laser spectroscopic measurements of the atomic level structure. ${ }^{[4]}$ All elements heavier than fermium have so far been produced only at accelerators in heavy ion fusion reactions. Up to element lawrencium $(Z=103)$, the identification of a new element and the assignment of the atomic number were made based on chemical properties. The position at which a newly discovered radioactive species was eluted from a cation-exchange column in $\alpha$-hydroxyisobutyrate solution was indicative of its ionic radius and thus its position within the group of actinides..$^{[1]}$ The element with atomic number 101, mendelevium (Md), was the first for which only single atoms could be produced and analyzed. In an experiment about $10^{9}$ atoms of ${ }^{253}$ Es were bombarded with $\alpha$-particles $\left({ }^{4} \mathrm{He}^{2+}\right.$ ions $)$ to synthesize single atoms of Md. These were subsequently identified as single atoms after chemical isolation by their characteristic radioactive decay. ${ }^{[5]}$ This was the first of a long series of 'oneatom-at-a-time' chemistry experiments. In this case the classical mass action laws and the definitions of chemical equilibrium and partition coefficient are no longer valid. The question arose whether one single atom actually displays chemical properties and how typical these properties are compared to bulk properties and how they can be measured. It can be shown that partition coefficients can be defined for single atoms, if one replaces concentrations by probabilities to find a single atom in a given state, i.e. in the gas phase or adsorbed to a surface in gas-phase chemistry, or in the aqueous phase vs. the organic phase in a liquid-liquid extraction step. ${ }^{[6]}$ As will be discussed later, it is indeed possible to perform chemical experiments with only one single atom or molecule at a time and to quantitatively measure thermochemical properties, distribution coefficients, and so on. Such experiments need to be designed in such a manner that the atom under investigation has the possibility to probe its state repeatedly, such as in chromatography experiments.

After the discovery of lawrencium the quest for the synthesis of ever heavier elements shifted from chemical methods to nuclear physics, since the half-lives of the newly discovered nuclides became shorter and shorter with increasing atomic number. Also, the production rates were diminishing rapidly. Even the lightest transactinide element rutherfordium with atomic number 104 can be produced at best with a rate of $2 \mathrm{~min}^{-1}$ of accelerator beam time. Since the discoverer of a new element traditionally has the right to propose its name, the quest for new elements turned into a fierce competition between scientists of the United States and Russia during the Cold War era. The recipe for synthesis of new ele- 


\begin{tabular}{|c|c|c|c|c|c|c|c|c|c|c|c|c|c|c|c|c|c|}
\hline $\mathrm{H}$ & 2 & & & & & & & & & & & 13 & 14 & 15 & 16 & 17 & $\stackrel{2}{\mathrm{He}}$ \\
\hline 3 & 4 & & & & & & & & & & & \begin{tabular}{|l|}
5 \\
\end{tabular} & 6 & $\begin{array}{l}7 \\
\end{array}$ & 8 & 9 & 10 \\
\hline $\mathrm{Li}$ & $\mathrm{Be}$ & & & & & & & & & & & $B$ & C & $\mathrm{N}$ & $\mathrm{O}$ & $F$ & $\mathrm{Ne}$ \\
\hline 11 & 12 & & & & & & & & & & & 13 & 14 & 15 & 16 & 17 & 18 \\
\hline $\mathrm{Na}$ & $\mathrm{Mg}$ & 3 & 4 & 5 & 6 & 7 & 8 & 9 & 10 & 11 & 12 & $\mathrm{Al}$ & $\mathrm{Si}$ & $P$ & $S$ & $\mathrm{Cl}$ & $\mathrm{Ar}$ \\
\hline 19 & 20 & 21 & 22 & 23 & 24 & 25 & 26 & 27 & 28 & 29 & 30 & 31 & 32 & 33 & 34 & 35 & 36 \\
\hline K & $\mathrm{Ca}$ & Sc & $\mathrm{Ti}$ & V & $\mathrm{Cr}$ & $\mathrm{Mn}$ & $\mathrm{Fe}$ & Co & $\mathrm{Ni}$ & $\mathrm{Cu}$ & $\mathrm{Zn}$ & $\mathrm{Ga}$ & $\mathrm{Ge}$ & As & $\mathrm{Se}$ & $\mathrm{Br}$ & $\mathrm{Kr}$ \\
\hline 37 & 38 & 39 & 40 & $\overline{41}$ & 42 & 43 & 44 & 45 & 46 & 47 & 48 & 49 & 50 & 51 & 52 & 53 & 54 \\
\hline $\mathrm{Rb}$ & $\mathrm{Sr}$ & $Y$ & $\mathrm{Zr}$ & $\mathrm{Nb}$ & Mo & Tc & $\mathrm{Ru}$ & $\mathrm{Rh}$ & $\mathrm{Pd}$ & $\mathrm{Ag}$ & $\mathrm{Cd}$ & In & Sn & $\mathrm{Sb}$ & $\mathrm{Te}$ & I & $\mathrm{Xe}$ \\
\hline 55 & 56 & \begin{tabular}{|l}
$57-71$ \\
\end{tabular} & 72 & 73 & 74 & 75 & 76 & 77 & 78 & 79 & 80 & 81 & 82 & 83 & 84 & 85 & 86 \\
\hline $\mathrm{Cs}$ & $\mathrm{Ba}$ & $\mathrm{La}$ & $\mathrm{Hf}$ & $\mathrm{Ta}$ & W & $\mathrm{Re}$ & Os & Ir & $\mathrm{Pt}$ & $\mathrm{Au}$ & $\mathrm{Hg}$ & TI & $\mathrm{Pb}$ & $\mathrm{Bi}$ & Po & At & $\mathrm{Rn}$ \\
\hline 87 & 88 & \begin{tabular}{|l|}
$89-103$ \\
\end{tabular} & 104 & 105 & 106 & 107 & 108 & 109 & 110 & 111 & 112 & 113 & $\overline{114}$ & 115 & 116 & 117 & 118 \\
\hline $\mathrm{Fr}$ & $\mathrm{Ra}$ & $A c$ & $\mathrm{Rf}$ & $\mathrm{Db}$ & $\mathrm{Sg}$ & $\mathrm{Bh}$ & $\mathrm{Hs}$ & $\mathrm{Mt}$ & Ds & $\mathrm{Rg}$ & Cn & Uut & Uuq & Uup & Uuh & Uus & Uuo \\
\hline$(119)$ & $(120)$ & $(121-153)$ & (154) & (155) & (156) & (157) & $\overline{(158)}$ & (159) & $(160)$ & (161) & \begin{tabular}{|l}
$(162)$ \\
\end{tabular} & (163) & \begin{tabular}{|l|}
$(164)$ \\
\end{tabular} & \begin{tabular}{|l|}
$(165)$ \\
\end{tabular} & \begin{tabular}{|l|}
$(166)$ \\
\end{tabular} & \begin{tabular}{|l|}
$(167)$ \\
\end{tabular} & \begin{tabular}{||l|}
$(168)$ \\
\end{tabular} \\
\hline
\end{tabular}

\begin{tabular}{|c|c|c|c|c|c|c|c|c|c|c|c|c|c|c|c|c|}
\hline & 57 & 58 & 59 & 60 & 61 & 62 & 63 & 64 & 65 & 66 & 67 & 68 & 69 & 70 & 71 & \\
\hline Lanthanides & La & $\mathrm{Ce}$ & $\mathrm{Pr}$ & $\mathrm{Nd}$ & $\mathrm{Pm}$ & Sm & $\mathrm{Eu}$ & Gd & $\mathrm{Tb}$ & Dy & Ho & Er & $\mathrm{Tm}$ & $\mathrm{Yb}$ & Lu & \\
\hline Actinides & $\begin{array}{l}89 \\
\mathrm{Ac}\end{array}$ & 90 & $\begin{array}{l}91 \\
P_{2}\end{array}$ & 92 & 93 & 94 & $\begin{array}{l}95 \\
\Delta \mathrm{m}\end{array}$ & 96 & 97 & 98 & 99 & 100 & 101 & 102 & 103 & \\
\hline & $\frac{\text { AC }}{(121)}$ & $\frac{111}{(122)}$ & $\frac{P d}{(123)}$ & $\frac{U}{(124)}$ & $\frac{\mathrm{Np}}{(125)}$ & $\mathrm{Pu}$ & Am & $\mathrm{Cm}$ & BK & $C_{T}$ & ES & rm & IVIa & NO & $\mathrm{Lr}$ & \\
\hline
\end{tabular}

Fig. 1. A modern Periodic Table of the Elements (adapted from a figure originally published by Seaborg et al. $\left.{ }^{[1]}\right)$. Elements with atomic numbers 113 and above have been reported but are not authenticated by the International Union of Pure and Applied Chemistry (IUPAC). In groups 4 to 8 and 12 , the transactinide element was experimentally shown to exhibit similar chemical properties as the lighter homologs.

ments of both competitors was the same. The heaviest, most neutron-rich available target materials such as ${ }^{242} \mathrm{Pu},{ }^{243} \mathrm{Am},{ }^{248} \mathrm{Cm}$, or even ${ }^{249} \mathrm{Cf}$ were bombarded with intense heavy ion beams of ${ }^{18} \mathrm{O}$ or ${ }^{22} \mathrm{Ne}$ ions. Due to changes in the average binding energy of the nucleons the products of complete fusion of projectile and target at an energy surmounting the repulsive Coulomb barrier are formed with an excess energy of about $50 \mathrm{MeV}$. Such high excitation energies lead to considerable losses due to sequential fission compared to the deexcitation by the evaporation of neutrons. On the average, about five neutrons are emitted before the excitation energy drops below the fission barrier, which implies that only one out of about $10^{9}$ formed fusion products survives. With the discovery of element 106 (seaborgium, $\mathrm{Sg}$ ) in 1974[7] this competition came to an end. The technological developments were exhausted and the available projectile and target combinations did not yield any detectable heavier element.

With the advent of more powerful heavy ion accelerators and physical separator systems, a new concept could be explored, which ultimately led to the discovery of another six new elements at the
Gesellschaft für Schwerionenforschung (GSI), Darmstadt, Germany. ${ }^{[8]}$ If the doubly magic nucleus ${ }^{208} \mathrm{~Pb}$, or nearby ${ }^{209} \mathrm{Bi}$ are used as target materials, and these are bombarded with heavy projectiles such as ${ }^{54} \mathrm{Cr}$, ${ }^{58} \mathrm{Fe}$, or even ${ }^{70} \mathrm{Zn}$, the break-up of the magic proton and/or neutron shell requires so much energy that the fusion products can be obtained with a much lower excitation energy of only 15-20 MeV. Thus, only one or two neutrons need to be evaporated. Still, the fusion products of such reactions are relatively neutron-deficient, meaning rather short-lived. The formed fusion products were separated from the incoming beam and from abundant nucleon transferand fission products with the Separator for Heavy Ion reaction Products (SHIP) and detected in a segmented silicon detector. Two observations were of importance: i) the newly synthesized elements all decayed by the emission of one or several alphaparticles to already known lighter nuclei, thus pinpointing the mass number and also the atomic number of the synthesized nucleus, ii) none of the new nuclides decayed preferentially by spontaneous fission (SF) from the ground state. This implied that these nuclei were stabilized against fission by nuclear shell effects. All the isotopes of the newly discovered elements were very short-lived, with half-lives in the range of milliseconds, and only a few atoms were produced in month-long experiments. Prospects for experimental chemical investigations of elements beyond $\mathrm{Sg}(\mathrm{Z}=$ 106) were rather dim, with the exception of element 108 (hassium) where in the alpha-decay chain of the nuclide ${ }^{277} 112$ the isotope ${ }^{269} \mathrm{Hs}$ with a half-life of about $10 \mathrm{~s}$ was observed. However, only two decay chains were observed in about 50 days of beam time. Very recently, the International Union of Pure and Applied Chemistry (IUPAC) has accepted the name of copernicium $(\mathrm{Cn})$, suggested by the discoverers as the name for element 112. [9]

Once again, the possibilities to synthesize even heavier elements seemed to be exhausted. Attempts to synthesize element 113 in the reaction ${ }^{70} \mathrm{Zn}+{ }^{209} \mathrm{Bi}$ at GSI were not successful. Nevertheless, a rather unexpected development was reported by the Flerov Laboratory in Dubna, Russia. Instead of using a closed-shell target nucleus, they employed the doubly magic projectile ${ }^{48} \mathrm{Ca}$ and heavy, neutron-rich actinide targets such as ${ }^{238} \mathrm{U}$ or ${ }^{242,244} \mathrm{Pu}$ to synthesize 
superheavy elements with atomic numbers 112 and 114 with larger production cross sections than the so-called 'cold' fusion reactions used at GSI. First results indicated that the nuclide ${ }^{283} \mathrm{Cn}$ has a fantastically long half-life of about $5 \mathrm{~min}$ and decayed by $\mathrm{SF}$, while one atom of ${ }^{289} 114$ lived longer than $30 \mathrm{~s}$. Even though these results were published in renowned journals, ${ }^{[10]}$ these results could not be reproduced in independent experiments and it was feared that the group in Dubna had to face the same fiasco as the group in Berkeley, which was forced to retract an article about the alleged synthesis of element 118. ${ }^{[11]}$ In subsequent improved experiments the group in Dubna reported new decay data that was measured with a gas-filled magnetic separator system. In theses experiments several new nuclides were observed,[12] among them ${ }^{283} \mathrm{Cn}$ with a half-life of about $4 \mathrm{~s}$ and ${ }^{289} 114$ with a half-life of $2.6 \mathrm{~s}$. Both nuclides decayed by alpha-particle emission and were formed with production cross sections that were 5 to 10 times higher than those observed in cold fusion reactions for $\mathrm{Cn}$. So far, in two independent experiments the same decay characteristics for ${ }^{283} \mathrm{Cn}$ were indeed observed: first in a chemistry experiment ${ }^{[13]}$ and shortly after in an experiment conducted at SHIP. ${ }^{[14]}$ Also, an experiment at Berkeley was successful in confirming decay data for the nuclides ${ }^{286,287} 114$. $^{\text {[15] }}$ In the mean time, the group from Dubna published decay data on more than 45 new nuclides and the discovery of all elements from atomic number 113 up to 118 . Some of the nuclides observed had halflives as long as $30 \mathrm{~s}\left({ }^{281} \mathrm{Ds}\right)$. Unfortunately, all the decay chains ended with SF of a previously unknown nuclide, so that the connection to the known region of heavy nuclides could not be established. Also, a number of confirmation experiments have not yet been conducted due to the enormously long beam times required. Nevertheless, the community was absolutely stunned about this success. The relatively large production cross sections can only be explained by a larger survival probability of these superheavy nuclides compared to lighter ones. Indeed, already in the early sixties, the nuclear shell model predicted a so-called 'island of stability' at proton numbers between 114 and 126 (the exact location is still under debate) and neutron number 184 . Although, the newly discovered nuclides in Dubna are more neutron deficient, it appears as if the shores of this fabled island have indeed been reached. Modern shell model calculations ${ }^{[16]}$ that reproduce the observed decay properties of the heaviest nuclides rather accurately, predict the existence of heavy isotopes of elements 108 (Hs) or 110 (Ds) with halflives approaching tens of years! Although it might not be possible to find these ele- ments in nature, it might one day be possible to store such exotic atoms in traps and study their atomic properties in detail over an extended time period.

Is it indeed possible to study the chemical properties of single atoms or molecules and why is this interesting? As the case of the nuclear shell model demonstrated, it might be interesting to have a look at the answers that theoretical chemists give to predict the chemical properties of superheavy elements. Traditionally, the chemical properties of an unknown element and its compounds were predicted by exploiting the fundamental relationships of the physicochemical data of the elements and their compounds within the groups and the periods of the Periodic Table. However, with the increasing nuclear charges in heavy elements, the innermost electrons become more tightly bound and are thus moving with velocities which are a considerable fraction of the speed of light. Therefore they obey the laws of relativistic quantum mechanics. Due to relativistic rearrangements, which are predicted for the electronic structure of the heaviest elements, quite unexpected chemical properties are to be expected. These so-called relativistic effects are already severely influencing the chemical properties of lighter elements such as gold. The yellow color and the rather inert chemical behavior can be attributed to relativistic effects and explained by fully relativistic quantum chemical calculations.[17] Early predictions of the chemical properties of superheavy elements were rather spectacular. One of the articles was entitled 'Are elements 112, 114, and 118 relatively inert gases?'. [18] Nowadays, with the use of powerful supercomputers the accuracy of quantum chemical calculations is increasing rapidly. Latest calculations come to the conclusion that element $112(\mathrm{Cn})$ is not completely inert as expected for a noble gas, but should form a chemical bond with $\mathrm{Au}$, which, however, is weaker than that of the lighter homolog $\mathrm{Hg} .{ }^{[19]}$ Also, element 114 might be relatively inert but should interact stronger with an Au surface than Cn. ${ }^{[19]}$ Element 118 is predicted to be the first element in the row of noble gases with an electron affinity. ${ }^{[20]}$ Due to the considerable experimental difficulties in experimentally studying the chemical properties of superheavy elements, the gap between experimental observables and theoretical predictions is still large.

The knowledge and understanding of the chemistry of the superheavy elements, especially of the early transactinides Rf, $\mathrm{Db}$, and $\mathrm{Sg}$ and their compounds, both experimentally and theoretically, is already quite extensive as documented by a first textbook entitled 'The Chemistry of Superheavy Elements' ${ }^{[21]}$ and several review articles (e.g. ref. [22]). While rapid, auto- mated chemical separations in aqueous solution were (and are) the method of choice for detailed investigations of $\mathrm{Rf}$ and $\mathrm{Db}$, the development of gas-phase chemical separation methods have allowed first chemical studies of heavier transactinide elements such as $\mathrm{Sg}, \mathrm{Bh}$, and Hs. The spectacular results obtained at Flerov Laboratory in Dubna using ${ }^{48} \mathrm{Ca}$ ion beams and actinide targets to synthesize relatively long-lived isotopes of $\mathrm{Cn}$ and 114 give chemists the perspective to experimentally investigate even the heaviest known elements. Very recently an experiment to elucidate for the first time the chemical properties of $\mathrm{Cn}$ was successful. ${ }^{[13]}$ Here, latest results on chemical experiments with elements Hs, $\mathrm{Cn}$, and 114 will be discussed.

\section{Experimental Techniques}

For chemical investigations, the element of interest has to be transported rapidly from the location of its production in a heavily shielded vault at the accelerator to a chemistry laboratory, or, the element has to be converted in situ to a chemical compound. Usually, the element of interest is transported attached to small aerosol particles in gas through a capillary to the chemistry laboratory. This transport can be accomplished within few seconds. Unfortunately, the transport yield is negatively affected by increasing beam intensities. The transport is unspecific, thus also undesired by-products of the nuclear reaction are transported. The harsh ionizing conditions created by the beam passing through the target recoil chamber severely limit the in situ synthesis of volatile transactinide compounds. In order to assess nuclides that are produced with few picobarn cross sections, the overall efficiency has to be as high as possible.

Luckily, chemists sometimes face very favorable and clear cut cases. Such a case constitutes the chemistry of Hs. If Hs has any resemblance to its lighter homolog Os, then it should also form tetroxides. Due to the perfect tetrahedral symmetry of $\mathrm{OsO}_{4}$, this compound only interacts very weakly with non-reducing surfaces and is therefore very volatile, similar to a noble gas. In experiments with $\mathrm{Hs}$, recoiling atoms were converted in situ with an admixture of $\mathrm{O}_{2}$ gas to the volatile $\mathrm{HsO}_{4}$. Another chemically very favorable case constitutes $\mathrm{Cn}$ as an expected homolog of Hg. Sufficiently volatile reaction products such as $\mathrm{Hg}$ and $\mathrm{Cn}$ can be transported directly with the flowing gas. It is well known that $\mathrm{Hg}$ interacts strongly with other metals such as $\mathrm{Zn}$ or $\mathrm{Au}$. Single atoms of $\mathrm{Hg}$ can be quantitatively adsorbed on an Au surface by diffusion-controlled deposition from a stream of He. The isolated atoms (or 


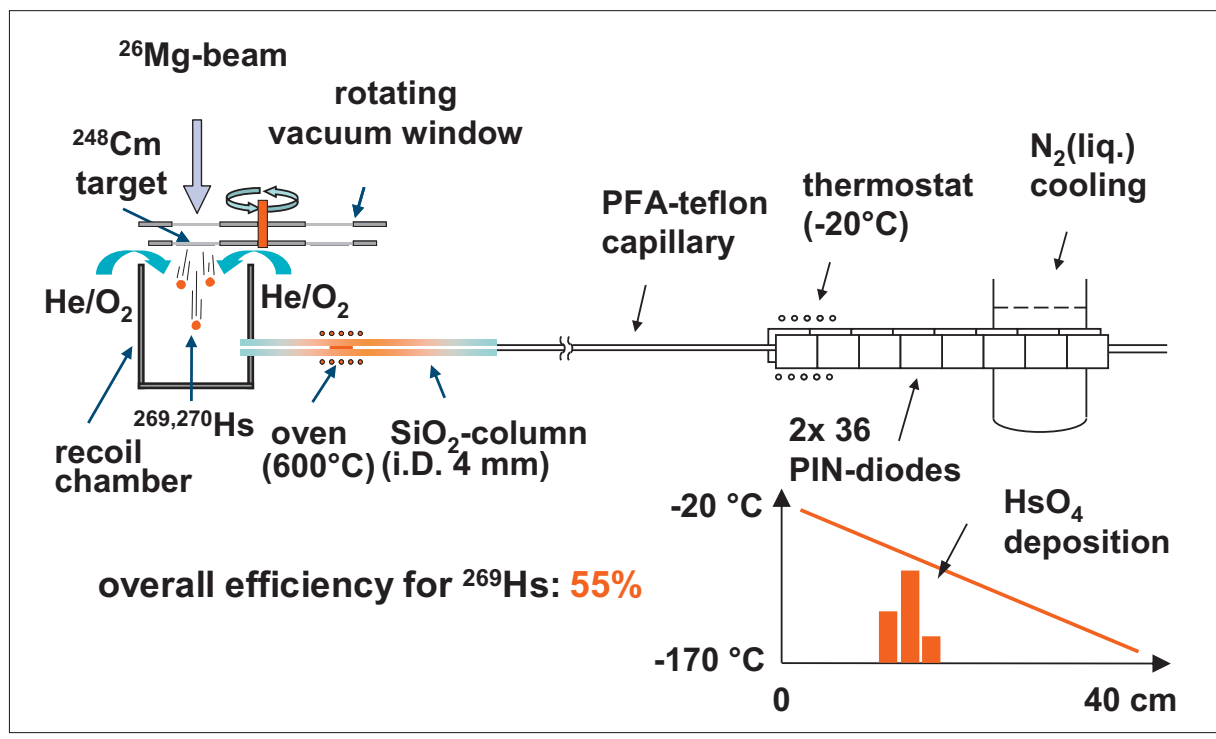

Fig. 2. The projectile beam from the accelerator (e.g. $\left.{ }^{26} \mathrm{Mg}\right)$ passed through the rotating vacuum window and the target assembly $\left(e . g .{ }^{248} \mathrm{Cm}\right)$. Nuclei formed in fusion reactions recoiled out of the target into a gas volume and were flushed with $\mathrm{He} / \mathrm{O}_{2}$ to a quartz column containing a quartz wool plug heated to $600{ }^{\circ} \mathrm{C}$ by an oven. There, $\mathrm{Hs}$ was converted to $\mathrm{HsO}_{4}$ which is volatile at room temperature and transported with the gas flow through a perfluoroalkoxy (PFA) capillary to the COLD or COMPACT detector array registering the nuclear decay $(\alpha-$-decay and SF). A thermostat kept the entrance of the array at $20^{\circ} \mathrm{C}$; the exit was cooled to $-170{ }^{\circ} \mathrm{C}$ by means of liquid nitrogen. Depending on the volatility of $\mathrm{HsO}_{4}$, the molecules adsorbed at a characteristic temperature. In experiments with $\mathrm{Cn}$ and element 114 the reactions ${ }^{242} \mathrm{Pu}\left({ }^{48} \mathrm{Ca}, 3 \mathrm{n}\right){ }^{287} 114$ and ${ }^{244} \mathrm{Pu}\left({ }^{48} \mathrm{Ca}, 4 \mathrm{n}\right)^{288} 114$ were used. The silicon detectors on one side of the detector channel were coated with a thin layer of gold and pure He was used as carrier gas.

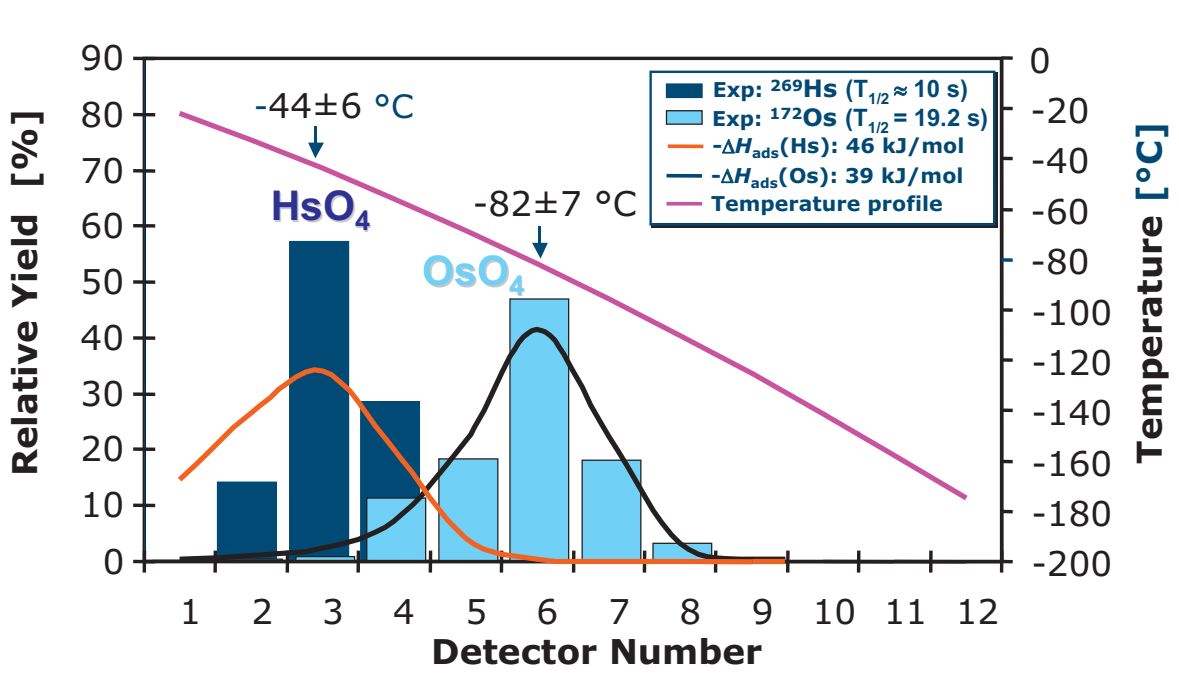

Fig. 3. Relative yields of $\mathrm{HsO}_{4}$ and $\mathrm{OsO}_{4}$ for each of the twelve detector pairs. Measured values are represented by bars: ${ }^{269} \mathrm{HsO}_{4}$ : dark blue; ${ }^{172} \mathrm{OsO}_{4}$ : light blue. The magenta line indicates the temperature profile (right-hand scale). The maxima of the deposition distributions were evaluated as $-44 \pm 6{ }^{\circ} \mathrm{C}$ for $\mathrm{HsO}_{4}$ and $-82 \pm 7^{\circ} \mathrm{C}$ for $\mathrm{OsO}_{4}$. Solid lines (red and black) represent results of a simulation of the adsorption process with $-\Delta H^{\mathrm{Si}_{3} \mathrm{~N}_{\mathrm{a}} \text { ads }}\left({ }^{269} \mathrm{HsO}_{4}\right)=46 \mathrm{~kJ} \cdot \mathrm{mol}^{-1}$ and $-\Delta H^{\mathrm{Si}_{3} \mathrm{~N}_{\mathrm{a}}{ }_{\mathrm{ads}}}$ $\left({ }^{172} \mathrm{OsO}_{4}\right)=39 \mathrm{~kJ} \cdot \mathrm{mol}^{-1}$, respectively. ${ }^{[23]}$

molecules) are detected in a thermochromatography detector. A negative longitudinal temperature gradient is established along an open column through which the carrier gas containing the isolated volatile atoms or molecules is flowing. Volatile species are deposited in the chromatography column according to their volatility, forming distinct deposition peaks. If the column consists of silicon detectors, then the nuclear decay of the separated nuclides can be registered. The detector number indicates the temperature at which the volatile compound was deposited. Thus, every detected nuclide reveals chemical information. A schematic of the In situ Volatiliza- tion and On-line detection (IVO) technique is shown in Fig. 2. This set-up was used for the first chemical identification of hassium. ${ }^{23]}$ The overall efficiency (including detection of a complete three-member $\alpha$-particle decay chain) is of the order of $55 \%$. A similar set-up using gold-covered silicon detectors was used for the first successful chemical identification of $\mathrm{Cn}^{[13]}$ and element 114.[24]

\section{First Chemical Identification of Hassium and Copernicium}

The first chemical identification of $\mathrm{Hs}^{[23]}$ and $\mathrm{Cn}^{[13]}$ signify the most important accomplishments of heavy element chemistry in past years. Even though only few single atoms can be obtained using the most favorable production reactions, an unambiguous identification of the nuclides ${ }^{269} \mathrm{Hs}$ and ${ }^{283} \mathrm{Cn}$ was achieved after chemical separation.

In an experiment conducted in 2001 at GSI by an international collaboration using the IVO technique, a total of seven decay chains attributed to ${ }^{269} \mathrm{Hs}$ were registered. ${ }^{[23]}$ The registered decay sequences were in good agreement with the lower end (after two alpha decays) of the decay chains attributed in earlier experiments to the nuclide ${ }^{277} \mathrm{Cn}$. Thus, the chemistry experiments gave supporting evidence for the first identification of element 112 at the SHIP separator of GSI Darmstadt. ${ }^{[9]}$ In Fig. 3 the distribution of decay chains along the temperature gradient is shown in comparison with the adsorption peak of $\mathrm{OsO}_{4}$. Surprisingly, $\mathrm{HsO}_{4}$ is slightly less volatile than $\mathrm{OsO}_{4}$. Applying a microscopic model of the adsorption process first thermochemical properties of $\mathrm{HsO}_{4}$ could be deduced from only seven registered atoms! The standard adsorption enthalpy of $\mathrm{HsO}_{4}$ on a silicon nitride surface was determined as $-\Delta H^{S i_{3} N_{4}} a d s\left({ }^{269} \mathrm{HsO}_{4}\right)=$ $46 \pm 2 \mathrm{~kJ} \cdot \mathrm{mol}^{-1}$.

The lower volatility of $\mathrm{HsO}_{4}$ compared to $\mathrm{OsO}_{4}$ is not due to relativistic effects. Adsorption of closed-shell spherically symmetric molecules with inert surfaces is governed by van der Waals forces, which can be calculated using a model of molecule-slab interaction. It can be shown that the molecule-surface interaction energy is determined by the relativistic (or nonrelativistic) $\mathrm{R}_{\max }$ of the valence $d$ orbitals, which are changing in the same manner down group 8.[25]

In 2006 and 2007 a series of experiments performed at FLNR Dubna allowed the unambiguous detection of an isotope of $\mathrm{Cn}$ after chemical separation. ${ }^{[13]}$ These experiments were conducted with the isotope ${ }^{283} \mathrm{Cn}$. It decays with a half-life of about $3.8 \mathrm{~s}$ by alpha-particle emission to ${ }^{279} \mathrm{Ds}$, 

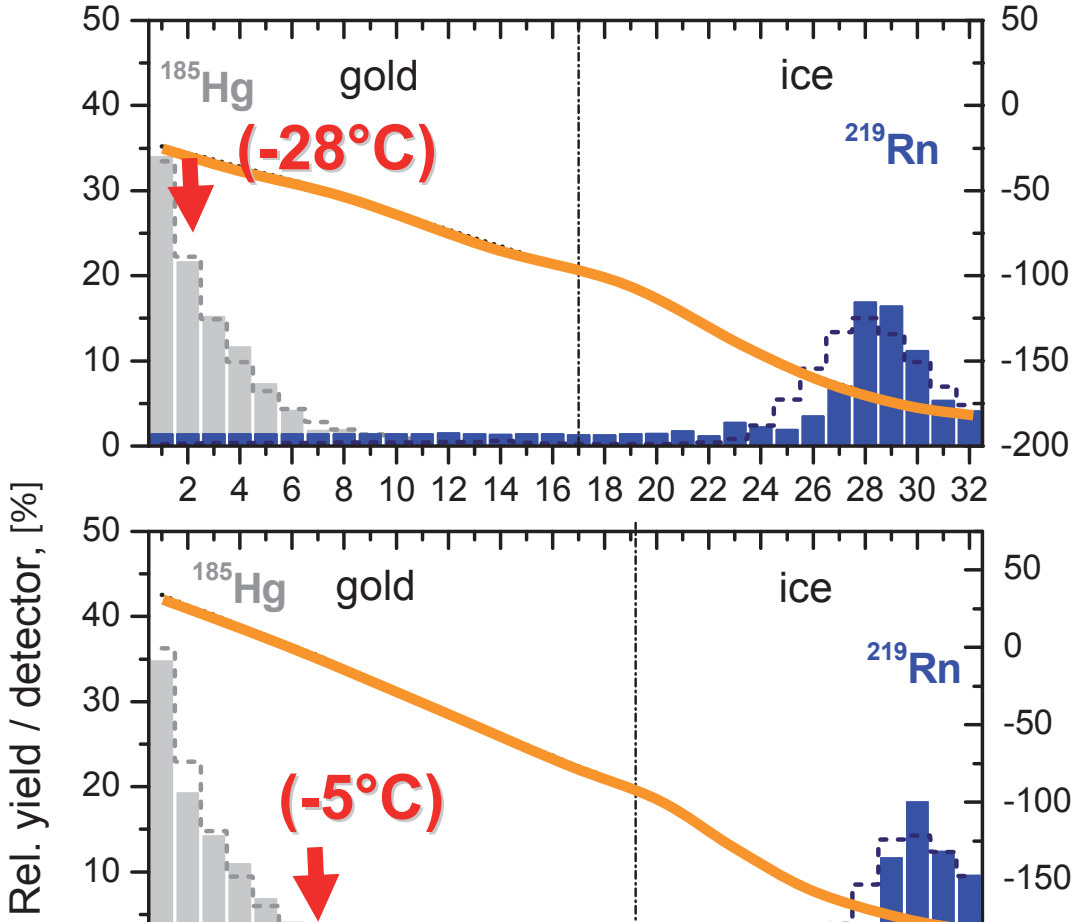

$246 \quad 6 \quad 8 \quad 101214161820222426283032$

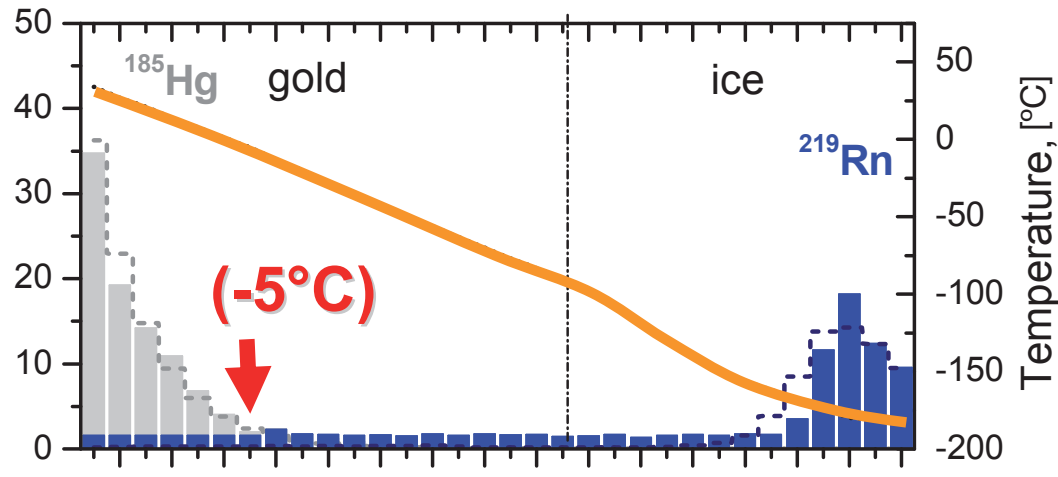

$2 \quad 4 \quad 6 \quad 8 \quad 101214161820222426283032$

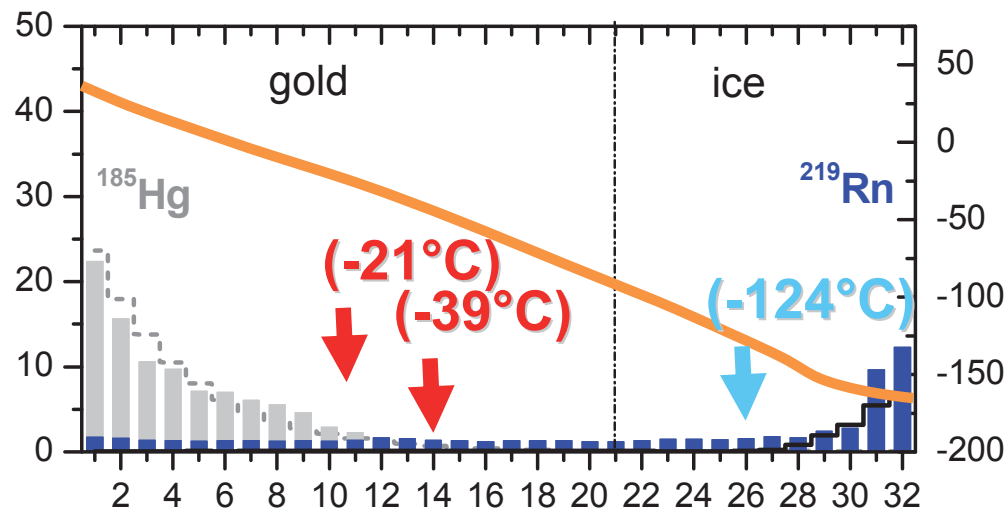

Detector \#

Fig. 4. Deposition patterns for ${ }^{185} \mathrm{Hg}$ (grey) and ${ }^{219} \mathrm{Rn}$ (blue) observed in thermo-chromatography experiments with $\mathrm{Cn}$. Indicated are the deposition temperatures of the five events attributed to ${ }^{283} \mathrm{Cn}$ (in red). The temperature profile is shown in orange. Dashed lines represent results of a simulation of the adsorption process for ${ }^{185} \mathrm{Hg}$ and ${ }^{219} \mathrm{Rn}$. For details see text and ref. [13].

which undergoes SF with a half-life of about $200 \mathrm{~ms}$. Larger production rates were observed by using the indirect production path ${ }^{242} \mathrm{Pu}\left({ }^{48} \mathrm{Ca}, 3 \mathrm{n}\right){ }^{287} 114\left(\mathrm{t}_{1 / 2}=0.48 \mathrm{~s}\right) \stackrel{a}{\longrightarrow}$ ${ }^{283} \mathrm{Cn}$. Thus, this reaction was used in this work. Recoiling atoms of ${ }^{287} 114$ were thermalized in dry He gas, where ${ }^{287} 114$ rapidly decayed to longer-lived ${ }^{283} \mathrm{Cn}$. Volatile $\mathrm{Cn}$ atoms were transported to a thermochromatography set-up, which contained Aucoated silicon detectors. The same applied for the lighter homolog element $\mathrm{Hg}$ and the heavy noble gas Rn. A total of five decay chains attributed to ${ }^{283} \mathrm{Cn}$ were observed. The distribution of the events along the thermochromatography detector is shown in Fig. 4. In the first experiment, the temperature gradient started at $-24^{\circ} \mathrm{C}$ and the first event was detected near the entrance at $-28{ }^{\circ} \mathrm{C}$. The nuclide ${ }^{185} \mathrm{Hg}$ was deposited immediately on the $\mathrm{Au}$ surface and its pattern corresponded to that expected for a spontaneous diffusion controlled deposition process. In contrast, ${ }^{219} \mathrm{Rn}$ was deposited at the cold end of the detector. Subsequently the entrance temperature of the column was raised to $+35^{\circ} \mathrm{C}$. As a consequence part of the Rn-peak was cut off. A second event was observed at $-5{ }^{\circ} \mathrm{C}$. The gas flow rates were $860 \mathrm{ml} /$ $\min$ and $890 \mathrm{ml} / \mathrm{min}$ respectively. In the 2007 experiments the gas flow rate was in- creased to $1500 \mathrm{ml} / \mathrm{min}$. Three additional events were observed, one at $-21^{\circ} \mathrm{C}$, one at $-39^{\circ} \mathrm{C}$, and the last one at $-124^{\circ} \mathrm{C}$, while a major part of ${ }^{219} \mathrm{Rn}$ was no longer adsorbed in the detector. Since it was experimentally not possible to lower the dew point of the carrier gas below $-100{ }^{\circ} \mathrm{C}$, the $\mathrm{Au}$ surface of the detectors below $-100{ }^{\circ} \mathrm{C}$ was covered with a very thin layer of water ice. The last event was interpreted as the adsorption of $\mathrm{Cn}$ on ice, which is expected to occur at lower temperatures than on $\mathrm{Au}$. From the measured adsorption temperatures a standard adsorption enthalpy of $\mathrm{Cn}$ on gold surfaces of $-\Delta H^{\mathrm{Au}}{ }_{\text {ads }}(\mathrm{Cn})=52^{+4}{ }_{-3} \mathrm{~kJ} \cdot \mathrm{mol}^{-1}$ was deduced.

This value indicates a somewhat lower volatility than was calculated using density functional methods, where the adsorption of $\mathrm{Cn}$ on a gold cluster containing up to 120 $\mathrm{Au}$ atoms was investigated theoretically. ${ }^{[19]}$ The authors predicted an adsorption position of $\mathrm{Cn}$ between $\mathrm{Hg}$ and $\mathrm{Rn}$ and gave $-\Delta H^{\mathrm{Au}}(\mathrm{Cn})=44 \mathrm{~kJ} \cdot \mathrm{mol}^{-1}$. In conclusion it can be stated that $\mathrm{Cn}$ is forming metallic bonds with $\mathrm{Au}$ which are weaker than for the homolog $\mathrm{Hg}$. But $\mathrm{Cn}$ is chemically not as inert as a noble gas, as was initially suggested. ${ }^{[18]}$

\section{Experiments with Element 114}

The next heavier element currently under investigation is element 114 , which would be placed as eka- $\mathrm{Pb}$ into group 14 of the Periodic Table. Suitable nuclides for chemical experiments are ${ }^{287} 114\left(\mathrm{~T}_{1 / 2}=0.5\right.$ $\mathrm{s}),{ }^{288} 114\left(\mathrm{~T}_{1 / 2}=0.8 \mathrm{~s}\right)$ or ${ }^{289} 114\left(\mathrm{~T}_{1 / 2}=2.6\right.$ s) which can be synthesized in the reaction ${ }^{48} \mathrm{Ca}+{ }^{242} \mathrm{Pu}$ or ${ }^{244} \mathrm{Pu}$. In a first publication, observation of three atoms of element 114 was reported in an experiment at FLNR similar to the ones performed for $\mathrm{Cn} .{ }^{[24]}$ From these three events an adsorption enthalpy of $-\Delta H^{\mathrm{Au}}{ }_{\text {ads }}(\mathrm{E} 114)=34^{+20}{ }_{-3} \mathrm{~kJ} \cdot \mathrm{mol}^{-1}$ was deduced for the adsorption on an $\mathrm{Au}$ surface. If true, this result would be very puzzling, since eka-Pb is expected to be more reactive than $\mathrm{Cn}$ and should thus deposit at higher temperatures than $\mathrm{Cn}$. Also, theoretical calculations which predicted the adsorption of $\mathrm{Cn}$ sufficiently accurately, predict $-\Delta H^{\mathrm{Au}}(\mathrm{E} 114)=68 \mathrm{~kJ} \cdot \mathrm{mol}^{-1}$, somewhat less volatile than $\mathrm{Cn}$. Due to the fact that a background made the positive identification of element 114 events more difficult than in the case of $\mathrm{Cn}$, this first result was met with some skepticism.

In order to remove this background, the very successful chemical techniques developed so far are coupled to a physical preseparator, such as a gas-filled separator. At GSI Darmstadt the dedicated gas-filled separator TASCA (Trans Actinide Separator and Chemistry Apparatus) was constructed and successfully commissioned. ${ }^{[26]}$ 
Recoiling fusion products are separated from the incoming beam and from transfer reaction products with a dipole magnet and focused on a relatively small product beam spot by two quadrupole magnets. The separator is operated as gas-filled separator which allows charge focusing. The separated product beam is passed through a thin window supported by a honeycomb structure into a gas volume. The windows can stand pressures well above 1 atm. These so-called recoil transfer chambers replace the target chambers used previously. The lower overall efficiency, which now also includes the transmission through the separator, is compensated by the removal of the primary beam and interfering transfer reaction products. A first chemical experiment with element 114 using thermochromatography on Au surfaces has been conducted behind the TASCA separator at GSI Darmstadt in fall of 2009, and first results from this experiment will be published in the near future.

\section{Outlook and Conclusions}

Due to the discovery of relatively long-lived superheavy nuclei (half-lives of seconds), first chemical experiments with these exotic elements have become reality. Nevertheless, due to the extremely low statistics in these experiments, chemical investigations were and will remain challenging. Presently, mainly the production process has to be optimized. This requires substantial investments in new, much more powerful accelerators and the development of the corresponding target technologies, so that the very precious target materials can be safely irradiated. In addition, the chemical separation procedures have to become even faster. One possibility is the use of vacuum thermochromatography, which should allow the investigation of nuclides with half-lives as short as about $100 \mathrm{~ms}$. It appears today that the experimental chemical investigation of the complete 7 th row of the Periodic Table will not just remain a dream, but become reality within the next decades.

Received: March 17, 2010
[1] G. T. Seaborg, W. D. Loveland, 'The Elements Beyond Uranium', Wiley-Interscience, New York, 1990, p. 100.

2] D. C. Hoffman, F. O. Lawrence, J. L. Mewherter, F. M. Rourke, Nature 1971, 234132.

[3] J. Lachner, I. Dillmann, T. Faestermann, U. Gerstmann, G. Korschinek, C. Lierse von Gostomski, M. Poutivtsev, G. Rugel, A. Türler, 'Annual Report Maier-Leibnitz-Laboratorium der Universität München und der Technischen Universität München', 2008, p. 28

[4] M. Sewtz, H. Backe, A. Dretzke, G. Kube, W. Lauth, P. Schwamb, K. Eberhardt, C. Grüning, P. Thörle, N. Trautmann, P. Kunz, J. Lassen, G. Passler, C. Z. Dong, S. Fritzsche, R. G. Haire, Phys. Rev. Lett. 2003, 90, 163002.

[5] A. Ghiorso, B. G. Harvey, G. R. Choppin, S. G. Thomson, G. T. Seaborg, Phys. Rev. 1950, 98, 1518 .

[6] D. Trubert, C. Le Naour, in 'The Chemistry of Superheavy Elements', Ed. M. Schädel, Kluwer Academic Publishers, Dordrecht, 2003, p. 95.

[7] A. Ghiorso, J. M. Nitschke, J. R. Alonso, C. T. Alonso, M. Nurmia, G. T. Seaborg, E. K. Hulet, R. W. Lougheed, Phys. Rev. Lett. 1974, 33, 1490.

[8] S. Hofmann, in 'The Chemistry of Superheavy Elements', Ed. M. Schädel, Kluwer Academic Publishers, Dordrecht, 2003, p. 1.

[9] K. Tatsumi, J. Corish, Pure Appl. Chem. 2010, $82,753$.

[10] Y. T. Oganessian, A. V. Yeremin, A. G. Popeko, S. L. Bogomolov, G. V. Buklanov, M. L. Chelnokov, V. I. Chepigin, B. N. Gikal, V. A. Gorshkov, G. G. Gulbekian, M. G. Itkis, A. P. Kabachenko, A. Y. Lavrentev, O. N. Malyshev, J. Rohac, R. N. Sagaidak, S. Hofmann, S. Saro, G. Giardina, K. Morita, Nature 1999, 400, 242.

[11] V. Ninov, K. E. Gregorich, W. Loveland, A. Ghiorso, D. C. Hoffman, D. M. Lee, H. Nitsche, W. J. Swiatecki, U. W. Kirbach, C. A. Laue, J. L. Adams, J. B. Patin, D. A. Shaughnessy, D. A Strellis, P. A. Wilk, Phys. Rev. Lett. 2002, 89 , 039901-1.

[12] Y. Oganessian, J. Phys. G: Nucl. Part. Phys. 2007, 34, R165.

[13] a) R. Eichler, N. V. Aksenov, A. V. Belozerov, G. A. Bozhikov, V. I. Chepigin, S. N. Dmitriev, R. Dressler, H. W. Gäggeler, V. A. Gorshkov, F. Haenssler, M. G. Itkis, A. Laube, V. Y. Lebedev, O. N. Malyshev, Y. T. Oganessian, O. V. Petrushkin, D. Piguet, P. Rasmussen, S. V. Shishkin, A. V. Shutov, A. I. Svirikhin, E. E. Tereshatov, G. K. Vostokin, M. Wegrzecki, A V. Yeremin, Nature 2007, 447, 72; b) R. Eichler, N. V. Aksenov, A. V. Belozerov, G. A. Bozhikov, V. I. Chepigin, S. N. Dmitriev, R. Dressler, H. W. Gäggeler, A. V. Gorshkov, M. G. Itkis, F. Haenssler, A. Laube, V. Y. Lebedev, O. N. Malyshev, Y. T. Oganessian, O. V. Petrushkin, D. Piguet, A. G. Popeko, P. Rasmussen, S V. Shishkin, A. A. Serov, A. V. Shutov, A. I Svirikhin, E. E. Tereshatov, G. K. Vostokin, M. Wegrzecki, A. V. Yeremin, Angew. Chem., Int. Ed. 2008, 47, 3262.
[14] S. Hofmann, D. Ackermann, S. Antalic, H. G. Burkhard, V. F. Comas, R. Dressler, Z. Gan, S. Heinz1, J. A. Heredia, F. P. Heßberger, J. Khuyagbaatar, B. Kindler, I. Kojouharov, P. Kuusiniemi, M. Leino, B. Lommel, R. Mann, G. Münzenberg, K. Nishio, A. G. Popeko, S. Saro, H. J. Schött, B. Streicher, B. Sulignano, J. Uusitalo, M. Venhart, A. V. Yeremin, Eur. Phys. J. A 2007, 32, 251.

[15] L. Stavsetra, K. E. Gregorich, J. Dvorak, P. A. Ellison, I. Dragojević, M. A. Garcia, H. Nitsche, Phys. Rev. Lett. 2009, 103, 132502.

[16] R. Smolańczuk, Phys. Rev. C 1997, 56, 812.

[17] E. Eliav, U. Kaldor, P. Schwerdtfeger, B. A. Hess, Y. Ishikawa, Phys. Rev. Lett. 1994, 73, 3203.

[18] K. S. Pitzer, J. Chem. Phys. 1975, 63, 1032.

[19] V. Pershina, J. Anton, T. Jacob, J. Chem. Phys. 2009, 131, 084713 .

[20] E. Eliav, U. Kaldor, Y. Ishikawa, P. Pyykkö, Phys. Rev. Lett. 1996, 77, 5350.

[21] S. Hofmann, V. Pershina, D. Trubert, C. Le Naour, A. Türler, K. E. Gregorich, J. V. Kratz, B. Eichler, R. Eichler, H. W. Gäggeler, G. Herrmann, in 'The Chemistry of Superheavy Elements', Ed. M. Schädel, Kluwer Academic Publishers, Dordrecht, 2003.

[22] M. Schädel, Angew. Chem., Int. Ed. 2006, 45, 368.

[23] C. E. Düllmann, W. Brüchle, R. Dressler, K. Eberhardt, B. Eichler, R. Eichler, H. W. Gäggeler, T. N. Ginter, F. Glaus, K. E. Gregorich, D. C. Hoffman, E. Jäger, D. T. Jost, U. W. Kirbach, D. M. Lee, H. Nitsche, J. B. Patin, V. Pershina, D. Piguet, Z. Qin, M. Schädel, B. Schausten, E. Schimpf, H.-J. Schött, S. Soverna, R. Sudowe, P. Thörle, S. N. Timokhin, N. Trautmann, A. Türler, A. Vahle, G. Wirth, A. B. Yakushev, P. M. Zielinski, Nature 2002, 418, 859.

[24] R. Eichler, N. V. Aksenov, Y. V. Albin, A. V. Belozerov, G. A. Bozhikov, V. I. Chepigin, S. N. Dmitriev, R. Dressler, H. W. Gäggeler, V. A. Gorshkov, R. A. Henderson, A. M. Johnsen, J. M. Kenneally , V. Y. Lebedev, O. N. Malyshev, K. J. Moody, Y. T. Oganessian, O. V. Petrushkin, D. Piguet, A. G. Popeko, P. Rasmussen, A. Serov, D. A. Shaughnessy, S. V. Shishkin, A. V. Shutov, M. A. Stoyer, N. J. Stoyer, A. I. Svirikhin, E. E. Tereshatov, G. K. Vostokin, M. Wegrzecki, P. A. Wilk, D. Wittwer, A. V. Yeremin, Radiochim. Acta 2010, 98, 133.

[25] V. Pershina, T. Bastug, B. Fricke, J. Chem. Phys. 2005, 122, 124301

[26] A. Semchenkov, W. Brüchle, E. Jäger, E. Schimpf, M. Schädel, C. Mühle, F. Klos, A. Türler, A. Yakushev, A. Belov, T. Belyakova, M. Kaparkova, V. Kukhtin, E. Lamzin, S. Sytchevsky, Nucl. Instr. Meth. B 2008, 266, 4153. 